\title{
Medicine shortages: a commentary on causes and mitigation strategies
}

\author{
Swathi lyengar, Lisa Hedman, Gilles Forte and Suzanne Hill ${ }^{*}$
}

\begin{abstract}
Shortages of medicines and vaccines have been reported in countries of all income levels in recent years. Shortages can result from one or multiple causes, including shortages of raw materials, manufacturing capacity problems, industry consolidation, marketing practices, and procurement and supply chain management. Existing approaches to mitigate shortages include advance notice systems managed through medicine regulatory authorities, special programmes that track medicines, and interventions to improve efficiency of the medicine supply chain. Redistribution of supplies at the national level can mitigate some shortages in the short term. International redistribution and exceptional regulatory approvals may be used in limited circumstances, with the understanding that such approaches are complex and may introduce cost and quality risks. If it is necessary to prioritise patients to receive a medicine that is in shortage, evidence-based practice should be used to ensure optimal allocation. Important steps in reducing medicine shortages and their impact include identifying medicines that are most at risk, developing reporting systems to share information on current and emerging shortages, and improving data from medicine supply chains.
\end{abstract}

Keywords: Shortage, Essential medicines, Ethics, Supply chain management

\section{Background}

Shortages of medicines and vaccines have been reported in countries of all income levels in recent years. For example, in 2013, Kerala, India, faced a shortage of 130 medicines on the state's Essential Medicines List and Rationalized Drug List when suppliers did not respond to state tenders [1]. Chemotherapeutic agents, generic injectables, and epilepsy medications continue to be in short supply across North America for reasons ranging from manufacturing problems to low commercial interest $[2,3]$. The BCG vaccine, critical in childhood immunization and also in the treatment of bladder cancer, has been in shortage across multiple markets since 2012 due to manufacturing quality problems combined with high demand [4].

Medicine shortages result from single or multiple causes, ranging from problems at the production level to weak supply chains that prevent medicines from reaching points of care. Irrespective of the causes, shortages lead to increased costs for health systems. The additional labour cost of responding to shortages in the United States was estimated at US\$ 216 million per annum by

*Correspondence: hills@who.int

World Health Organization, 2027 Avenue Appia, Geneva CH-1211, Switzerland
Kaakeh et al. [5]. Other costs to health systems include higher prices of substitute medicines, as well as costs of treating adverse reactions, medication errors, and consequences of delayed therapy [6]. Shortages may also lead to prescribers and dispensers substituting medicines that are not clinically appropriate.

In this article, we outline the causes of shortages and the existing solutions to mitigate these, as well as the ethical considerations and the actions taken by the global community to manage shortages.

\section{Reasons for shortages}

Shortages result from one or more causes [7], including manufacturing issues, acute healthcare needs, external political and economic factors, or marketing, procurement, and supply chain management practices. Examples of manufacturing issues resulting in shortages include a lack of raw materials, limited manufacturing capacity, or product quality problems resulting in more stringent inspections and plant closures. Health emergencies, such as disasters and disease outbreaks, can also trigger shortages due to unexpected and large surges in demand [7]. Similarly, changes in recommended clinical practices can dramatically impact availability; for example, when 
the United Kingdom recommended inclusion of the meningitis $B$ vaccine in the childhood immunization programme in 2015 , a surge in demand led to a shortage of supply [8].

Industry consolidation has led to fewer manufacturers for older, often less profitable medicines [9]. Consolidations may also lead to new regulatory applications and transfers in marketing authorization, with resulting requirements for regulatory assessment [10]. Incomplete or delayed regulatory submissions may delay marketing authorization and potentially lead to national supply shortages. Factors such as poor financial incentives for manufacturers, changes in reimbursement, changes in regulatory requirements, and costs required to correct manufacturing errors can decrease the availability of medicines [9]. If profit margins are low, for example due to either competition or price controls, the expenses required to ensure good manufacturing practices [11] may not be covered and, therefore, keeping production lines in operation may not be viable [12].

At present, there is no global system to capture data or trends on shortages, which compromises efforts to respond to or prevent them; some national early warning systems do exist, but only from a limited number of countries and programs. Additionally, the criteria for what constitutes a medicine at high risk of shortage may differ from region to region.

\section{Management of shortages}

Efforts to avoid and mitigate shortages include advance notice systems to national medicines regulatory authorities (NMRAs), as well as special initiatives that monitor stock levels of specific medicines. Data from medicine supply chains are important for maintaining and forecasting supply. Advance notice systems with NMRAs exist mainly in high-income markets and require manufacturers to advise them regarding impending shortages [13]. Responses from NMRAs include identifying clinically acceptable substitute medicines, providing notifications to prescribers and dispensers, facilitating exceptional market authorizations for other producers and, in some cases, identifying other manufacturing capacities; however, NMRAs do not have legislative authority to compel a manufacturer to produce.

Professional associations, such as the American Society of Health-System Pharmacists (ASHSP) and the Association Africaine des Centrales d'Achats de Médicaments Essentiels (ACAME), an association of central medical stores across Africa, have mechanisms for sharing information among members. The ASHSP collates and reports national wholesale level shortages and publishes these online [14]. Similarly, ACAME shares information on pricing, procurement sources, availability, quality, and technical specifications of medicines. One of its aims is to coordinate demand across countries as a means of reducing shortages at wholesale and supply chain levels in the region [15]. These types of systems are also useful in managing shortages, for example, by identifying alternative sources of products. However, this information comes primarily from procurement and logistics management information systems, which may not immediately signal that a shortage is caused by a manufacturing problem.

Data from the medicines supply chain are useful, particularly for analysing trends and maintaining appropriate supply levels to prevent avoidable shortages [16]. Still, challenges with unavailable or unreliable supply chain data have persisted for decades [17]. Monitoring the supply chain may also allow countries to redistribute medicines across warehouses or health facilities, as well as to manage emergency orders when necessary. In theory, countries could work together to mitigate shortages by sharing or redistributing inventories; however, this option would require regulatory agreements and may introduce extra costs and quality risks [7]. Illegal diversion of stock may create or exacerbate shortages in the originating country, distort overall demand, and may result in the introduction of substandard, spurious, falsely labelled, falsified, or counterfeit (SSFFC) products into the supply chain $[18,19]$.

Ethical approaches to managing medicines in short supply can be complicated, as seen, for example, in the inactivated polio vaccine and cancer therapies shortages across multiple countries $[20,21]$. An ethical framework to ensure equity, fairness and public health interest is therefore important in managing a shortage [22]. For example, the allocation of medicines may be guided by evidence that prioritizes high-risk groups [23] or, in other cases, to groups that would have greater therapeutic benefit.

\section{Future directions and conclusions}

Addressing medicine and vaccine shortages is a multifaceted issue. Ensuring access to essential medicines and health technologies is a target of the Sustainable Development Goals [24]. In addition to improving the quality and scope of a country's national supply chain data, international collaboration is required in order to manage large-scale shortages. Further, definitions of shortages and stock-outs must be harmonized to develop effective cross-country interventions. Similarly, medicines most at risk of global shortages, especially those without clinically acceptable substitutes, must be identified and prioritized for global action. With an improved understanding of the gaps in current information on the causes of shortages and noting the benefits of global communication, countries may also consider supporting the development of a global earlywarning shortage notification system to identify substitutes, alternative suppliers, or other mitigation measures. In the 
context of minimizing the risk of SSFFC, countries may consider implementing 'track and trace' systems for medicines. These types of mechanisms promote robust data collection and can strengthen good governance and accountability in the pharmaceutical sector. It is equally important that countries promote the optimal use of medicines to ensure accurate and clinically appropriate demand. Ultimately, policy mechanisms and harmonization efforts should emphasize their support for good manufacturing practices, appropriate supply chain management and security, and the coordination of strategies for the notification of shortages.

\section{Authors' contributions}

All authors contributed to the writing of the manuscript. All authors agree with the manuscript's results and conclusions. All authors have read, and confirm that they meet, ICMJE criteria for authorship. All authors have read and approved the final manuscript for publication.

\section{Authors' information}

Swathi lyengar, Lisa Hedman, Gilles Forte, and Suzanne Hill are WHO employees. The conclusions in this manuscript are theirs as individuals and do not represent WHO policy.

\section{Competing interests}

The authors declare that they have no competing interests.

Received: 24 June 2016 Accepted: 18 August 2016

Published online: 29 September 2016

\section{References}

1. Assary G. Acute shortage of essential drugs. Deccan Chronicle. 24 Nov 2013. http://www.deccanchronicle.com/131124/news-current-affairs/article/acuteshortage-essential-drugs. Accessed 16 Mar 2016.

2. Fink S. Drug shortages forcing hard decisions on rationing treatments. New York Times. 29 Jan 2016. http://www.nytimes.com/2016/01/29/us/drugshortages-forcing-hard-decisions-on-rationing-treatments.html?_r=0. Accessed 16 Mar 2016.

3. Ross M. What can the new minister of health do about drug shortages? Huffington Post Canada. 29 Jan 2016. http://www.huffingtonpost.ca/marvinross/canada-minister-of-health-drug-shortages_b_9391512.html. Accessed 16 Mar 2016.

4. Wheeler M. BCG Vaccine Live Intravesical. Current Shortages Bulletin. Bethesda: American Society of Health System Pharmacists; 2016. http:// www.ashp.org/menu/DrugShortages/CurrentShortages/Bulletin.aspx?id=915. Accessed 11 May 2016

5. Kaakeh R, Sweet BV, Reilly C, Bush C, DeLoach S, Higgins B, Clark AM, Stevenson J. Impact of drug shortages on U.S. health systems. Am J Health Syst Pharm. 2011;68(19):1811-9. doi:10.2146/ajhp110210.

6. McLaughlin M, Kotis D, Thomson K, Harrison M, Fennessy G, Postelnick M, Scheetz MH. Effects on patient care caused by drug shortages: a survey. J Manag Care Pharm. 2013;19(9):783-8. doi:10.18553/jmcp.2013.19.9.783.

7. Fox ER, Birt A, James KB, Kokko H, Salverson S, Soflin DL. ASHP Guidelines on Managing Drug Product Shortages in Hospitals and Health Systems. Am J Health Syst Pharm. 2009:66(15):1399-406. doi:10.2146/aihp090026.

8. Meningitis B. Is there enough vaccine to go round? BBC News. 18 February 2016. http://www.bbc.com/news/uk-england-35603938. Accessed 16 Mar 2016.

9. Ventola CL. The drug shortage crisis in the United States: causes, impact, and management strategies. P T. 2011;36(11):740-57.

10. Demirtshyan M. Impact of regulatory affairs during M\&A in life sciences organizations. iMedGlobal. 25 Aug 2015. http://www.imedglobal.com/ managing-consolidations-in-life-sciences-industry-does-it-need-an-unbiasedapproach/. Accessed 16 Mar 2016.

11. World Health Organization. WHO good manufacturing practices for pharmaceutical products: main principles. Geneva: WHO; 2014. http://www. who.int/medicines/areas/quality_safety/quality_assurance/TRS986annex2.pdf. Accessed 16 Mar 2016.
12. Mrazek M, Fidler A. Access to pharmaceuticals and regulation in the Commonwealth of Independent States. In: Mossialos E, Mrazek M, Walley T, editors. Regulating pharmaceuticals in Europe: striving for efficiency, equity, and quality. England: Open University Press; 2004.

13. World Health Organization. Addressing the global shortages of medicines, and the safety and accessibility of children's medication - EB138/41. Geneva: WHO; 2015. http://apps.who.int/gb/ebwha/pdf_files/EB138/B138_41-en.pdf. Accessed 16 Mar 2016.

14. American Society of Health System Pharmacists. Drug Shortages. http://www.ashp.org/menu/DrugShortages. Accessed 16 Mar 2016.

15. ACAME. Mot du Secrétaire Permanent. http://www.acame.net/acame/spip. php?article1. Accessed 16 Mar 2016.

16. Lufesi NN, Andrew M, Aursnes I. Deficient supplies of drugs for life threatening diseases in an African community. BMC Health Serv Res. 2007;7:86. doi:10.1186/1472-6963-7-86

17. Systems for Improved Access to Pharmaceutical and Services (SIAPS) Program. Promising Practices: Data Management. Arlington: Management Sciences for Health; 2014. http://siapsprogram.org/wp-content/uploads/ 2014/07/6_Data-Management-final.pdf. Accessed 16 Mar 2016.

18. Birgli AG. An evaluation of medicines shortages in Europe with a more in-depth review of these in France, Greece, Poland, Spain, and the United Kingdom. Zurich: Birgli AG; 2013. http://static.correofarmaceutico.com/docs/ 2013/10/21/evaluation.pdf. Accessed 16 Mar 2016.

19. Mackey TK, Liang BA, York P, Kubic T. Counterfeit drug penetration into global legitimate medicine supply chains: a global assessment. Am J Trop Med Hyg. 2015:92(6):59-67. doi:10.4269/aitmh.14-0389.

20. Patel M, Orenstein W. A world free of polio - the final steps. N Engl J Med. 2016;374(6):501-3.

21. International Pharmaceutical Federation. Report of the International Summit on Medicines Shortage. The Hague: International Pharmaceutical Federation 2013. https://www.fip.org/files/fip/publications/FIP_Summit_on_Medicines_ Shortage.pdf. Accessed 5 August 2016.

22. Gibson JL, Bean S, Chidwick P, Godkin D, Sibbald RW, Wagner F. Ethical framework for resource allocation during a drug supply shortage. Healthc $Q$. 2012:15(3):26-35. doi:10.12927/hcq.2013.23040.

23. Rosoff PM. Unpredictable drug shortages: an ethical framework for short-term rationing in hospitals. Am J Bioeth. 2012;12(1):1-9. doi:10.1080/15265161.2011. 634483

24. World Health Organization. Addressing the global shortage of medicines and vaccines - WHA69.25. Geneva: WHO; 2016. http://apps.who.int/gb/ ebwha/pdf_files/WHA69/A69_R25-en.pdf. Accessed 1 June 2016.

Submit your next manuscript to BioMed Central and we will help you at every step:

- We accept pre-submission inquiries

- Our selector tool helps you to find the most relevant journal

- We provide round the clock customer support

- Convenient online submission

- Thorough peer review

- Inclusion in PubMed and all major indexing services

- Maximum visibility for your research

Submit your manuscript at www.biomedcentral.com/submit 